\title{
Scoping Review of Hospital Business Continuity Plans to Validate the Improvement after the 2011 Great East Japan Earthquake and Tsunami
}

\author{
Hiroyuki Sasaki, ${ }^{1,2}$ Hiroaki Maruya, ${ }^{3}$ Yoshiko Abe, ${ }^{2,4}$ Motoo Fujita, ${ }^{2,5}$ \\ Hajime Furukawa, ${ }^{2,5}$ Mikiko Fuda, ${ }^{2,6}$ Takashi Kamei, ${ }^{2,7}$ Nobuo Yaegashi, ${ }^{2,8}$ \\ Teiji Tominaga ${ }^{2,9}$ and Shinichi Egawa ${ }^{1,2}$

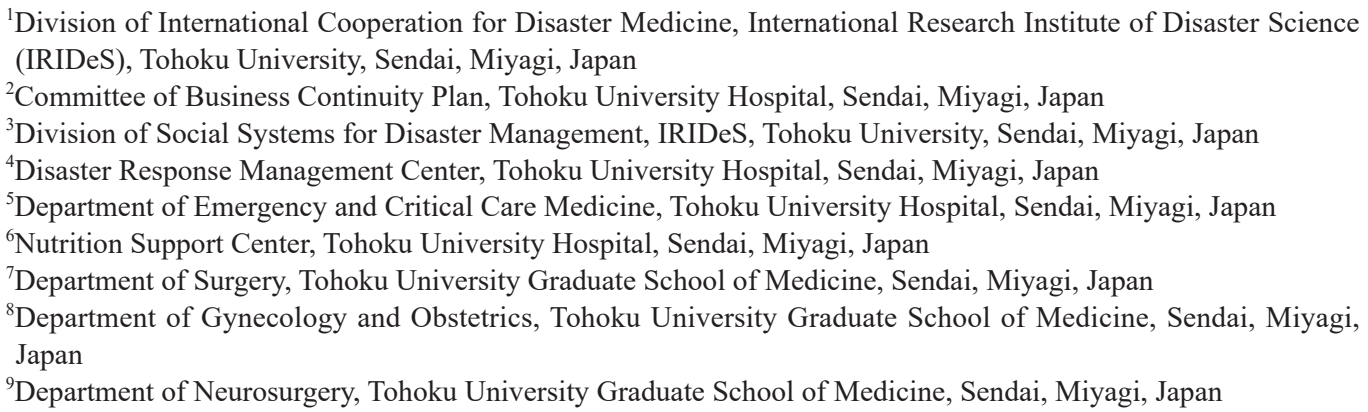

During a disaster, all hospitals are expected to function as "social critical institutions" that protect the lives and health of people. In recent disasters, numerous hospitals were damaged, and this hampered the recovery of the affected communities. Had these hospitals business continuity plans (BCPs) to recover quickly after the disaster, most of the damage could have been avoided. This study conducted a scoping review of the historical trend and regional differences in hospital BCPs to validate the improvement of the BCP concept based on our own experience at Tohoku University Hospital, which was affected by the 2011 Great East Japan Earthquake and Tsunami (GEJET). We searched PubMed by using keywords related to BCP and adapted 97 articles for our analysis. The number of articles on hospital BCPs has increased in the 2000s, especially after Hurricane Katrina in 2005. While there are regional specificity of hazards, there were many common topics and visions for BCP implementation, education, and drills. From our 2011 GEJET experience, we found that BCPs assuming region-specific disasters are applicable in various types of disasters. Thus, we suggest the following integral and universal components for hospital BCPs: (1) alternative methods and resources, (2) priority of operation, and (3) resource management. Even if the type and extent of disasters vary, the development of BCPs and business continuity management strategies that utilize the abovementioned integral components can help a hospital survive disasters in the future.

Keywords: alternative methods and resource; business continuity plan (BCP); disaster medicine; priority of operation; scoping review

Tohoku J. Exp. Med., 2020 July, 251 (3), 147-159.

\section{Introduction}

During a catastrophe, be it a natural or manmade disaster, all hospitals are expected to operate as "social crit- ical institutions" that protect the lives and health of the affected people (WHO, World Health Organization 2015). The healthy status of the affected people leads to quick recovery of the affected community. But are hospitals cur-

Received January 29, 2020; revised and accepted June 10, 2020. Published online July 9, 2020; doi: 10.1620/tjem.251.147.

Correspondence: Hiroyuki Sasaki, Division of International Cooperation for Disaster Medicine, International Research Institute of Disaster Science (IRIDeS), Tohoku University, 468-1 Aramaki-Aoba, Aoba-ku, Sendai, Miyagi 980-8572, Japan.

e-mail: hsasa@surg.med.tohoku.ac.jp

(C)2020 Tohoku University Medical Press. This is an open-access article distributed under the terms of the Creative Commons Attribution-NonCommercial-NoDerivatives 4.0 International License (CC-BY-NC-ND 4.0). Anyone may download, reuse, copy, reprint, or distribute the article without modifications or adaptations for non-profit purposes if they cite the original authors and source properly.

https://creativecommons.org/licenses/by-nc-nd/4.0/ 
rently strong enough to effectively withstand disaster? The answer is "No." Current disaster countermeasures implemented by hospitals have not been enough.

In 2018, Japan experienced many natural disasters, and hospital business continuity (BC) began facing several new challenges. On June 18, 2018, a large earthquake during a morning commute in north Osaka stopped traffic, and this resulted in hospital dysfunction owing to the lack of hospital staff (Hirata and Kimura 2018). In July, some hospitals in west Japan lost power supply because of torrential rains that lasted for days, causing both a flood and landslides. Those hospitals had their emergency power generators on the first floor, which were inundated because of the unexpected flooding (Oda et al. 2019; Sato and Imamura 2019). On September 6, an earthquake of magnitude M6.7 in Hokkaido caused the shutdown of a thermal power plant and resulted in the blackout of the entire Hokkaido Island. The blackout ceased the functioning of many medical devices (e.g., mechanical ventilators, artificial dialyzers) and put several patients' lives at risk. Although the hospital buildings did not collapse structurally, we experienced a paralysis of hospital functions, as though it were a "functional disease of a society."

Modern hospitals need to be equipped with a wide range of structural, non-structural, and functional capacities. As a result of diverse specialties and functional advancements in medical fields, medical operations have been subdivided, and many kinds of specialists, including non-medical staff (e.g., maintenance, inspection, and cleaning staff, and security guards), are essential. Medical devices depend heavily on their lifelines, namely electricity, gas, and water supply. If these lifelines or commute systems in the area are shut down, the hospitals that have not prepared for this situation cannot function, as it was in Osaka and Hokkaido. No hospital can function alone in an area, especially during a disaster. For a hospital to function, it needs a strong network and the support of relevant organizations including medical, non-medical, and lifeline supply chains.

The concept of $\mathrm{BC}$ is different from conventional disaster prevention. We have to ask "by what time," "by which alternative means," and "to what extent" we should recover our business from the perspective of organizational functions and processes including input and output. In Japan, business continuity plans (BCPs) were introduced as countermeasures in the fields of information security, earthquakes, and pandemics such as the influenza in the 2000s (Ministry of Economy, Trade and Industry 2005; Interministerial Avian Influenza Committee 2007). After the 2011 Great East Japan Earthquake and Tsunami (GEJET) that affected all of the east of Japan and either destroyed or functionally impaired a number of hospitals (Ishigaki et al. 2013; Egawa et al. 2018), a momentum toward developing hospital BCPs grew, drawing influence from the prevalence of BCPs in other business fields including factories, supply chains, social lifeline utility, communication, and transport
(Cabinet Office, Government of Japan 2013). In the medical field, health care workers started to consider how and when we should strive to recover our businesses and to what extent it would be possible with restricted human and material resources. Yamanouchi et al. advocated that all hospitals, including small and psychiatric ones, should have BCPs to survive on their own for several days, in order to reduce "preventable disaster death (PDD)" after the investigation of the affected hospitals caused by the 2011 GEJET (Yamanouchi et al. 2015, 2017). PDD refers to death during a disaster that can be prevented under a normal hospital situation and with appropriate systems. They identified 125 PDD cases in the hospitals in Miyagi prefecture that had been devasted by the 2011 GEJET. Currently in Japan, every disaster base hospital (DBH), which plays a key role in disaster case management, is expected to establish its own BCP and training in addition to ensuring a seismic structure and sufficient equipment to meet certification requirements (Ministry of Health, Labour and Welfare 2018).

The state of hospital BCPs has been evolving rapidly both in Japan and world over. This article aims to perform a scoping review of historical trends, regional differences, and commonalities in hospital BCPs to validate the improvement of the hospital BCP concept based on our experience at the Tohoku University Hospital after the 2011 GEJET.

\section{Scoping Review of Past Hospital BCPs}

As of April 15, 2020, we searched PubMed using the terms "hospital business continuity," "business continuity plan," "safe hospital in disaster," and "business continuity in disaster." We identified 1452 articles, including some that overlapped. We excluded articles that have no valid abstract and that are not related to the themes of health, medicine, hospitals, and BCPs (Fig. 1). Finally, we analyzed 97 articles in this study. As hospital BCP is a localcontext dependent emerging field of research that is diverse, and that there are a wide range of hazard-contexts, a scoping review is more appropriate than a systematic review to identify gaps in the existing literature (Arksey and O'Malley 2005). Such a scoping study takes the process of dissemination one step further by drawing conclusions from the existing literature on the overall state of research activity. We designed this study to identify the trend and gaps in the evidence base where no research has been conducted, and summarized the research findings to validate our experience and the implementation of BCPs in our institution. This is not a systematic literature review based on the PRISMA statement (Moher et al. 2009). We followed Arksey and O'Malley's framework as far as possible, that is: identifying the research question, identifying relevant studies, selecting the studies, charting the data, and collating, summarizing, and reporting the results. Our research questions were: "What is the trend in hospital BCPs according to the type of hazard and local specificity? What is the most rele- 


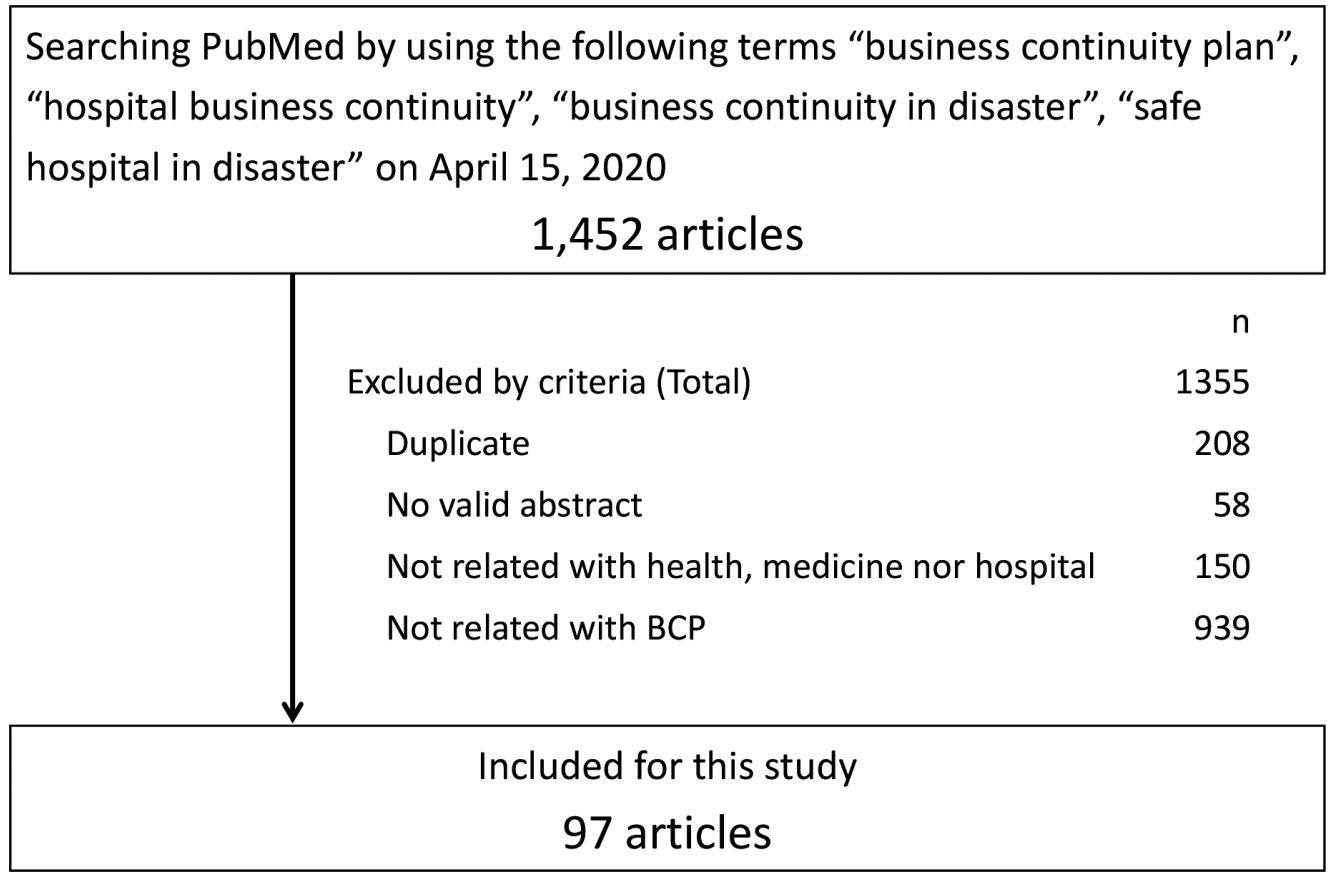

Fig. 1. Related articles identifying the process followed in this study.

We searched PubMed using BCP-related terms and identified 1452 articles, including overlapping ones. We excluded duplicates, articles with no valid abstract, articles that were not related to health, medical, or BCP fields. We included 97 articles in this study.

vant function of hospital BCPs in validating our own experience?"

\section{Historical trend}

There are a few articles on hospital BCPs in disaster management that were written before 1990. Some articles definitively titled "business continuity plans" in the public health and medical fields have been published since 1993 (Luecke and Hoopingarner 1993; Norcross et al. 1993). Since the late 2000s, BCP articles in the public health and medical fields have been published constantly, and the number increased in the 2010s (Fig. 2). As mentioned above, in Japan, the concept of BCP in other businesses began in the middle of the 2000s, but BCPs in the public health and medical fields were delayed. The articles on hospital BCP from Japan were published only after the 2011 GEJET caused significant damages to hospitals (Kudo et al. 2013; Kuroda et al. 2013a, b; Tomizuka et al. 2013; Suginaka et al. 2014; Matsumura et al. 2015; Yamanouchi et al. 2015, 2017; Sugishita et al. 2019; Takeuchi et al. 2019). Some authors have suggested that organizations that have experienced major disasters in the past can take stronger countermeasures in comparison with other organizations that did not experience such disasters (Seyedin et al. 2011). Fig. 2 shows that BCP articles were published constantly after Hurricane Katrina in 2005 (Perce 2007; Lowe 2009), and their number increased after the 2011 GEJET. Taking the increase in the number of instances of large-scale natural disaster in recent years and the establishment of the Sendai Framework for Disaster Risk Reduction 2015-2030
(UN-DRR 2015) into account, it is understandable that the number of hospital BCP articles doubled in the 2010s when compared with the 2000s. The Sendai Framework has framed one of its seven global targets to "substantially reduce disaster damage to critical infrastructure and disruption of basic services, among them health and educational facilities, including through developing their resilience by 2030." This, it intends to strengthen hospitals during disaster.

There is continuous research output on BCPs against infectious diseases (Tomizuka et al. 2013; Kandel 2015; Sugishita et al. 2019). The end of 2019 marked the spread of Coronavirus disease 19 (COVID-19). Though COVID19 has spread to all parts of the world, few papers have specifically addressed the relationship between COVID-19 response and hospital BCPs. On April 7, 2020, only one paper mentioned that the COVID-19 outbreak is an opportunity to review existing BCPs in order to address the pandemic (Koonin 2020). Many previous papers referring to infectious outbreaks (i.e., pandemic influenza) and hospital BCPs dealt with the stockpile of personal protective equipment and relocation plans for hospital staff when there were fewer staff members (Tomizuka et al. 2013; Abramovich et al. 2017).

\section{Main topics of $B C P$}

Focusing on the main topics of medical BCP articles after 2006, articles were consistently published on pandemics/infectious diseases (Horvath et al. 2006; Itzwerth et al. 2006) (Table 1). After the pandemic influenza outbreak in 


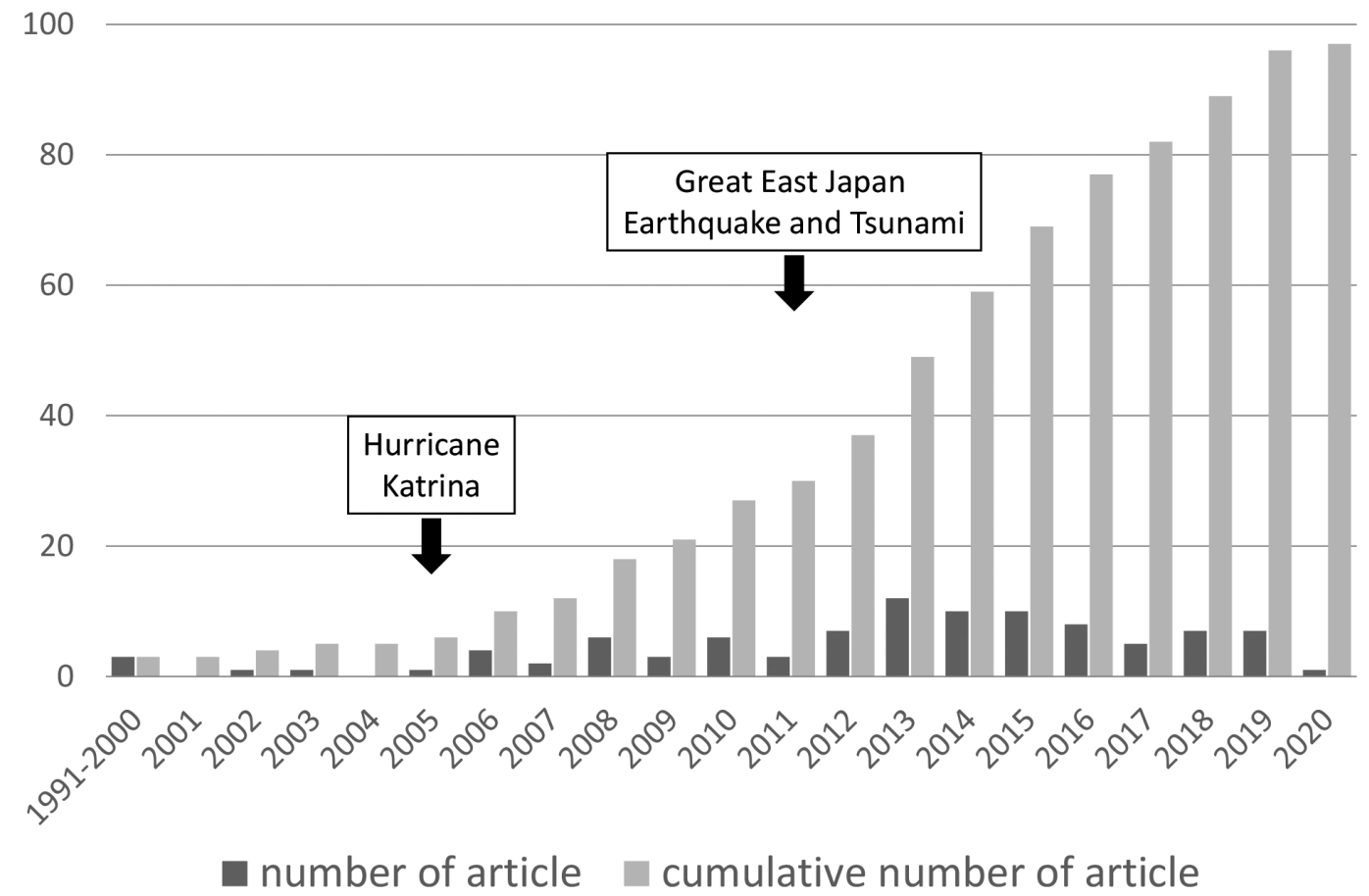

Fig. 2. Trends in the number of BCP articles in public health and medical fields. The dark bar indicates the annual number of $\mathrm{BCP}$ articles in the public health and medical fields, and the light bar indicates the cumulative number of $\mathrm{BCP}$ articles in public health and medical fields.

2009, 4 articles were published in 2010 (Roberts and Molyneux 2010; Sprung et al. 2010a, b; Zimmerman et al. 2010). In line with the development of electronic health and medical records, articles on cyber security and information technology (IT) have been on the rise (Gamble 2008; Gomes and Lapao 2008; Khorasani 2008) (Tables 1, 2). Some articles focused on the functional aspect, such as electronic records, picture archiving and communication systems (PACS), or other technical equipment that depend heavily on lifelines according to the development of the hospital information system (Langer et al. 2012; Hoffman et al. 2018; Takeuchi et al. 2019).

In 2015, the World Health Organization (WHO) revised the Hospital Safety Index Guide for evaluators (WHO 2015). Before and after this revision, the articles on hospital safety applying the WHO hospital safety index increased (Djalali et al. 2014; Heidaranlu et al. 2015; Asefzadeh et al. 2016) (Table 2).

The enhancement of recoverability measures and collaboration with the community and other businesses are also suggested. Several authors have advocated the establishment of community-wide planning that utilizes robust hospital buildings as the core of local disaster measures, with the aim of strengthening the connection with affiliated businesses and supply chains (Buehler et al. 2006; Graham and Connolly 2007; Paturas et al. 2010; Tosh et al. 2014; Landman et al. 2015; Morgan et al. 2015).

\section{Regional differences}

Table 3 shows the difference in the number of articles on hospital BCPs in each region. The largest number (44) of articles comes from North America followed by Asia (16), and next by articles that have a multinational focus (11).

In North America, articles on hurricanes, tornados, and typhoons and on the establishment of BCPs were published more consistently (Norcross et al. 1993; Eastman et al. 2007; Carlton and Bringle 2012; Christian et al. 2014; Hoffman et al. 2018; Seltenrich 2018; Newman and Gallion 2019) (Tables 3, 4). In Asia, a larger number of articles focused on earthquakes (Kudo et al. 2013; Suginaka et al. 2014; Matsumura et al. 2015; Yamanouchi et al. 2015, 2017), and the establishment of BCPs. In the Middle East, articles focused on Safe Hospitals, and on the Hospital Safety Index from the WHO (Park et al. 2010; Apisarnthanarak et al. 2013; Djalali et al. 2014; Ardalan et al. 2016; Asefzadeh et al. 2016).

There were a few articles from Europe, Oceania, and Central and South America (Table 3), as the types of hazards and medical and public health systems vary in local and regional contexts, and articles tend to deal with regionspecific hazards, as well as the local and regional contexts of vulnerability and coping capacity.

\section{Commonality}

Much of the literature, however, has followed an allhazards approach or has operated without specific assumptions of hazards because it is not possible to predict the type and extent of a particular hazard beforehand, and further, the unexpected damage and cascading events can change 
Table 1. Main topics of pubic health and medical BCP articles (historical - hazard).

\begin{tabular}{|c|c|c|c|c|c|c|c|c|c|c|c|c|c|}
\hline \multirow[b]{2}{*}{ Year } & \multirow[b]{2}{*}{$\begin{array}{l}\text { Number } \\
\text { of } \\
\text { articles }\end{array}$} & \multicolumn{12}{|c|}{ Hazard } \\
\hline & & Earthqake & Tsunami & Flood & Terror & $\begin{array}{l}\text { Manmade } \\
\text { disaster }\end{array}$ & $\begin{array}{c}\text { Pandemic/ } \\
\text { Infectious } \\
\text { disease }\end{array}$ & $\begin{array}{l}\text { Hurricane/ } \\
\text { Tornado/ } \\
\text { Typhooon }\end{array}$ & $\begin{array}{l}\text { Cyber } \\
\text { sequrity }\end{array}$ & $\begin{array}{l}\text { Mass } \\
\text { casualty } \\
\text { incident }\end{array}$ & $\begin{array}{c}\text { All } \\
\text { hazards }\end{array}$ & $\begin{array}{l}\text { No hazard } \\
\text { mentioned }\end{array}$ & Others \\
\hline $1991-2000$ & 3 & & & 1 & & & & 2 & & & & 1 & \\
\hline 2001 & & & & & & & & & & & & & \\
\hline 2002 & 1 & & & & 1 & 1 & & & & & & & \\
\hline 2003 & 1 & & & & & & & & & & & 1 & \\
\hline 2004 & & & & & & & & & & & & & \\
\hline 2005 & 1 & & & & & & & 1 & & & & & \\
\hline 2006 & 4 & & & & & & 2 & & & & 1 & 1 & \\
\hline 2007 & 2 & & & & & & 1 & 1 & & & & & \\
\hline 2008 & 6 & & & 1 & & 1 & 1 & & 1 & & 2 & 1 & \\
\hline 2009 & 3 & & & & & & & & & & 2 & 1 & \\
\hline 2010 & 6 & & & & & & 4 & & 1 & & & 1 & \\
\hline 2011 & 3 & 1 & & & & & & 1 & & & 1 & & \\
\hline 2012 & 7 & & & & & & & 2 & & & 1 & 4 & \\
\hline 2013 & 12 & 1 & 1 & 1 & & & 2 & & 1 & & & 7 & \\
\hline 2014 & 10 & 1 & 1 & & & & 1 & & & 1 & 4 & 3 & \\
\hline 2015 & 10 & 2 & 2 & 1 & 1 & & 1 & & & & 1 & 4 & \\
\hline 2016 & 8 & & & & & & & 2 & & & 4 & 2 & \\
\hline 2017 & 5 & 1 & 1 & & & & 1 & 1 & & & & 2 & \\
\hline 2018 & 7 & 1 & & & & & 1 & 2 & & 1 & & 1 & 1 \\
\hline 2019 & 7 & 1 & 1 & & & & 1 & 1 & 1 & & & 3 & \\
\hline 2020 & 1 & & & & & & & & & & & 1 & \\
\hline Total & 97 & 8 & 6 & 4 & 2 & 2 & 15 & 13 & 4 & 2 & 16 & 33 & 1 \\
\hline
\end{tabular}

the outcome, such as the nuclear power plant accident in the 2011 GEJET (Shibahara 2011).

Based on the change in hazards, hospital evacuation that constitutes a major burden for hospitals is a constant focus in the literature. Most articles on tropical cyclone disasters and hospital evacuations were published in North America, which focused on Hurricanes Katrina, Sandy, Harvey, and Irma, and are region-specific in relation to hospital BCPs (Icenogle et al. 2016; Hoffman et al. 2018; Seltenrich 2018; Newman and Gallion 2019). The American College of Chest Physicians (CHEST) statement focuses on the evacuation of critically ill patients in intensive care units (ICU) during a pandemic event or disaster; it also acknowledged that critical care providers receive little to no training on how to perform safe and effective ICU evacuations (King et al. 2014). King and the panel developed expert opinion-based suggestions using a modified Delphi process reaching 13 key suggestions including regional planning, evacuation drills, patient transport preparation and equipment, patient prioritization and distribution for evacuation, patient information and tracking, and federal and international evacuation assistance systems. There is a systematic literature review on the selection of hospital location (King et al. 2014; Moradian et al. 2017). Compared to the main determinants of cost and demand, the disaster risk fell down to the fifth frequent reason to decide the hospital site suggesting the need of advocacy of disaster risk reduction to health decision-makers.

The establishment of a BCP, together with training and drills, are common topics in the literature regardless of region. To make hospital BCPs more practical in case of disasters, it is essential to educate and train the hospital staff that carry it out. Some articles have pointed out the importance of pre-disaster education and training, such as the attachment and detachment skills of personal protective equipment during the outbreak of infectious diseases, and the flow of staff while receiving many injured patients in mass casualty incidents (Daugherty 2008; Kearns et al. 2014; Newman and Gallion 2019).

From the results of the scoping review, we found that even though the topics of BCP articles in the world differ according to region, type of hazard, as well as the local and regional contexts, there may be universal and common features of hospital BCPs.

Japan is located in "the ring of fire" that is an earthquake-prone area around the Pacific Ocean. The results of this scoping review validate our own practice of implementing hospital BCPs after the 2011 GEJET for more realistic preparedness, and BCM treating earthquakes as a most possible but not the only hazards. 
Table 2. Main topics of pubic health and medical BCP articles (historical - hard and softwear).

\begin{tabular}{|c|c|c|c|c|c|c|c|c|c|c|c|c|c|c|c|c|c|}
\hline \multirow[b]{2}{*}{ Year } & \multirow[b]{2}{*}{$\begin{array}{l}\text { Number } \\
\text { of } \\
\text { articles }\end{array}$} & \multicolumn{6}{|c|}{ Facility/Equipment/Hardwear } & \multicolumn{10}{|c|}{ Business continuity management/ Softwear } \\
\hline & & $\begin{array}{l}\text { Radiology/ } \\
\text { PACS }\end{array}$ & $\underset{\text { Cyber }}{\text { IT/ }}$ & Lifeline & $\begin{array}{c}\text { Safe } \\
\text { Hospital/ } \\
\text { HSI }\end{array}$ & Biobank & Stockpile & $\begin{array}{l}\text { Establish- } \\
\text { ment of } \\
\text { BCP }\end{array}$ & $\begin{array}{l}\text { Incidnet } \\
\text { command } \\
\text { system }\end{array}$ & $\begin{array}{l}\text { Surge } \\
\text { capacity }\end{array}$ & $\begin{array}{c}\text { Staff } \\
\text { relocation }\end{array}$ & $\begin{array}{c}\text { Protection/ } \\
\text { Decontami- } \\
\text { nation }\end{array}$ & Evacuation & $\begin{array}{c}\text { Education/ } \\
\text { drill }\end{array}$ & $\begin{array}{l}\text { Supply } \\
\text { chain }\end{array}$ & $\begin{array}{c}\text { District } \\
\text { Business } \\
\text { Continuity }\end{array}$ & Others \\
\hline $1991-2000$ & 3 & 1 & 1 & 1 & & & & 1 & & & & & 2 & & 1 & & \\
\hline 2001 & & & & & & & & & & & & & & & & & \\
\hline 2002 & 1 & & & & & & & & & & & 1 & & & & & \\
\hline 2003 & 1 & & 1 & & & & & & & & & & & & & & \\
\hline 2004 & & & & & & & & & & & & & & & & & \\
\hline 2005 & 1 & & & 1 & & & 1 & 1 & & & & & & & 1 & & \\
\hline 2006 & 4 & & & 1 & & & 1 & & & 1 & & 1 & & 2 & 2 & 1 & \\
\hline 2007 & 2 & & & & & & & 1 & & 1 & & & & & & 1 & \\
\hline 2008 & 6 & 1 & 3 & & 1 & & & 2 & & & & 1 & & 1 & & & \\
\hline 2009 & 3 & & 1 & 1 & 1 & & & 2 & 1 & & & & 2 & 1 & 1 & & \\
\hline 2010 & 6 & & 1 & & & & 2 & 4 & 3 & & 2 & & 1 & 1 & & 1 & \\
\hline 2011 & 3 & & & & & & 1 & 1 & 1 & 1 & 1 & & & 1 & & & \\
\hline 2012 & 7 & 2 & 1 & & 1 & & & 3 & & & & & 1 & & & & \\
\hline 2013 & 12 & & 4 & 1 & & & 4 & 6 & & & & & 1 & 1 & 1 & & 1 \\
\hline 2014 & 10 & 1 & 3 & 1 & 2 & & 3 & 5 & 1 & & & & 3 & 2 & 2 & & \\
\hline 2015 & 10 & & 2 & 4 & & & 4 & 5 & 1 & 1 & & & 1 & 1 & 2 & 1 & \\
\hline 2016 & 8 & & & & 4 & 1 & & 1 & 1 & & & & 1 & 3 & & & 2 \\
\hline 2017 & 5 & & 1 & 1 & 1 & & 2 & 1 & & & & & 1 & & 1 & & 1 \\
\hline 2018 & 7 & 1 & & 3 & 1 & & 2 & 2 & & 1 & 1 & & 2 & 1 & 1 & & 1 \\
\hline 2019 & 7 & 1 & 1 & & & 1 & 2 & 5 & 1 & 1 & 1 & & 2 & 3 & & & \\
\hline 2020 & 1 & & & & & & & & & 1 & & & & & & & \\
\hline Total & 97 & 7 & 19 & 14 & 11 & 2 & 22 & 40 & 9 & 7 & 5 & 3 & 17 & 17 & 12 & 4 & 5 \\
\hline
\end{tabular}

IT, information technology; PACS, Picture Archiving and Communication Systems; HSI, Hospital Safety Index (by World Health Organization).

Table 3. Main topics of pubic health and medical BCP articles (regional- hazard).

\begin{tabular}{|c|c|c|c|c|c|c|c|c|c|c|c|c|c|}
\hline \multirow[b]{2}{*}{ Region } & \multirow[b]{2}{*}{$\begin{array}{l}\text { Number } \\
\text { of } \\
\text { articles }\end{array}$} & \multicolumn{12}{|c|}{ Hazard } \\
\hline & & Earthqake & Tsunami & Flood & Terror & $\begin{array}{l}\text { Manmade } \\
\text { disaster }\end{array}$ & $\begin{array}{l}\text { Pandemic/ } \\
\text { Infectious } \\
\text { disease }\end{array}$ & $\begin{array}{c}\text { Hurricane/ } \\
\text { Tornado/ } \\
\text { Typhoon }\end{array}$ & $\begin{array}{c}\text { Cyber } \\
\text { sequrity }\end{array}$ & $\begin{array}{l}\text { Mass } \\
\text { casualty } \\
\text { incident }\end{array}$ & $\begin{array}{c}\text { All } \\
\text { hazards }\end{array}$ & $\begin{array}{l}\text { No hazard } \\
\text { mentioned }\end{array}$ & Others \\
\hline Asia & 16 & 5 & 5 & 1 & 1 & 1 & 3 & & 1 & & & 5 & \\
\hline Oceania & 4 & & & & & & 3 & & & & 1 & & \\
\hline North America & 44 & & & 2 & 1 & 1 & 5 & 13 & 1 & 2 & 4 & 16 & 1 \\
\hline $\begin{array}{c}\text { Central and South } \\
\text { America }\end{array}$ & 2 & 1 & & & & & & & & & 1 & & \\
\hline Europe & 5 & & & 1 & & & 1 & & 1 & & & 2 & \\
\hline Middle East & 10 & 1 & & & & & & & 1 & & 4 & 4 & \\
\hline Multinational & 11 & & & & & & 3 & & & & 5 & 3 & \\
\hline Unknown & 5 & 1 & 1 & & & & & & & & 1 & 3 & \\
\hline Total & 97 & 8 & 6 & 4 & 2 & 2 & 15 & 13 & 4 & 2 & 16 & 33 & 1 \\
\hline
\end{tabular}

\section{Implementation of Hospital BCPs at the Tohoku University Hospital after the 2011 GEJET}

A Process to develop Tohoku University Hospital BCP

Tohoku University Hospital (TUH) located in Sendai
City, Miyagi Prefecture, has 1,225 beds and approximately 3,000 staff and 120 departments. It is one of the largest hospitals in Japan. TUH was not inundated by the tsunami, but encountered the quake during the 2011 GEJET and lost gas and power supply. The emergency power generator 
Table 4. Main topics of pubic health and medical BCP articles (regional - hard and softwear).

\begin{tabular}{|c|c|c|c|c|c|c|c|c|c|c|c|c|c|c|c|c|c|}
\hline \multirow[b]{2}{*}{ Region } & \multirow[b]{2}{*}{$\begin{array}{l}\text { Number } \\
\text { of } \\
\text { articles }\end{array}$} & \multicolumn{6}{|c|}{ Facility/Equipment/Hardwear } & \multicolumn{10}{|c|}{ Business continuity management/ Softwear } \\
\hline & & $\begin{array}{l}\text { Radiology } / \\
\text { PACS }\end{array}$ & $\begin{array}{l}\text { IT/ } \\
\text { Cyber }\end{array}$ & Lifeline & $\begin{array}{c}\text { Safe } \\
\text { Hospital/ } \\
\text { HSI }\end{array}$ & Biobank & Stockpile & $\begin{array}{c}\text { Establish- } \\
\text { ment of } \\
\text { BCP }\end{array}$ & $\begin{array}{l}\text { Incidnet } \\
\text { command } \\
\text { system }\end{array}$ & $\begin{array}{c}\text { Surge } \\
\text { capacity }\end{array}$ & $\begin{array}{c}\text { Staff } \\
\text { relocation }\end{array}$ & $\begin{array}{c}\text { Protection/ } \\
\text { Decontami- } \\
\text { nation }\end{array}$ & Evacuation & $\begin{array}{l}\text { Education/ } \\
\text { drill }\end{array}$ & $\begin{array}{c}\text { Supply } \\
\text { chain }\end{array}$ & $\begin{array}{c}\text { District } \\
\text { Business } \\
\text { Continuity }\end{array}$ & Others \\
\hline Asia & 16 & 1 & 3 & 5 & & 1 & 6 & 9 & & & & 1 & 2 & 2 & 3 & & 1 \\
\hline Oceania & 4 & & & 2 & & & & 2 & & & & 1 & & 1 & 1 & & 1 \\
\hline North America & 44 & 6 & 12 & 6 & & 1 & 10 & 18 & 3 & 6 & 4 & 1 & 9 & 9 & 6 & 4 & 2 \\
\hline $\begin{array}{c}\text { Central and South } \\
\text { America }\end{array}$ & 2 & & & & 2 & & & & & & & & & & & & \\
\hline Europe & 5 & & 1 & & & & & 3 & 1 & & & & & & 1 & & \\
\hline Middle East & 10 & & 1 & 1 & 4 & & 2 & 2 & 1 & 1 & & & 1 & 1 & & & \\
\hline Multinational & 11 & & 1 & & 5 & & 3 & 3 & 3 & & 1 & & 4 & 2 & 1 & & \\
\hline Unknown & 5 & & 1 & & & & 1 & 3 & 1 & & & & 1 & 2 & & & 1 \\
\hline Total & 97 & 7 & 19 & 14 & 11 & 2 & 22 & 40 & 9 & 7 & 5 & 3 & 17 & 17 & 12 & 4 & 5 \\
\hline
\end{tabular}

IT, information technology; PACS, Picture Archiving and Communication Systems; HSI, Hospital Safety Index (by World Health Organization).

immediately replaced the electricity for critical hospital functions. TUH had an aseismic structure and, fortunately, had no casualties among inpatients and staff. TUH dispatched medical staff to inland and coastal hospitals affected by the 2011 GEJET, and accepted a large number of patients from coastal hospitals (Satomi 2011). However, unforeseen problems arose. Long-term disruption of social utility systems and the elevator impelled us to recognize that it is critical to establish countermeasures for human and material resources to inspect, maintain, and recover hospital functions in addition to an aseismic structure (Kudo et al. 2013, 2014; Nakagawa et al. 2013; Furukawa et al. 2014; Matsumura et al. 2015).

Based on this experience of the 2011 GEJET, TUH decided to establish an original hospital BCP in 2014. After carrying out investigations and other procedures, we established the first TUH BCP in 2017 (Tohoku University Hospital 2019). Herein, we describe the key steps in the development and improvement of our hospital BCP after the 2011 GEJET (Fig. 3).

\section{1) Establishment of the BCP Committee}

First, addressing BCP development and business continuity management (BCM) is an indispensable official task of the hospital. We established the permanent $\mathrm{BCP}$ Committee (Fig. 3, Step 1). It is critical to obtain a consensus and a budget from the hospital executives for the activities of the committee. Thus, the vice hospital director in charge of disaster countermeasures took on the task of committee chairperson. Over 20 representatives from the departments that play key roles in disaster response (i.e., emergency room, operation room, ICU, laboratories, radiology department, medical engineers, nurse directors, dieticians, administrators, and so on) were chosen as committee members. Several members including administrative officers also served as secretaries to assist in the execution of the tasks of each department.

A brief committee meeting for confirmation and approval of the activity was held once a month. In this monthly meeting, task provision and summary of investigations were discussed (detailed later). Each committee member provided the aggregated results of the investigations conducted by each department based on their real experiences and official records of the 2011 GEJET.

\section{2) Review of critical operations/estimated recovery time objective (RTO)}

We first defined the fundamental role of TUH in disaster as a DBH and the largest academic and educational tertiary hospital in the area to: (1) protect the security and life of patients, family members, students, and staffs in disaster, (2) contribute to the community by medical and public health response, (3) cooperate with and support the community, (4) protect the community by preventing the contamination of hazardous materials from the hospital, and (5) quickly recover clinical, research, and educational activities.

Each committee member concretely listed departmentspecific critical operations by classifying their operations into "Routine operations that cannot be halted even during a disaster" and "New operations that are necessary after the onset of a disaster." Each committee member was asked to estimate the type of influence on the patient's health and life according to the downtime of critical operations. It was acceptable if the restoration or continuity of critical operations, to some extent using alternative ways or things, before the patient's situation became irreversible (Fig. 3, Step 2). We decided RTO based on these estimations and finalized the "list of total reviews of critical operations." Thereby, in-hospital department-specific critical operations that have to be performed preferentially were visualized (Fig. 4). 


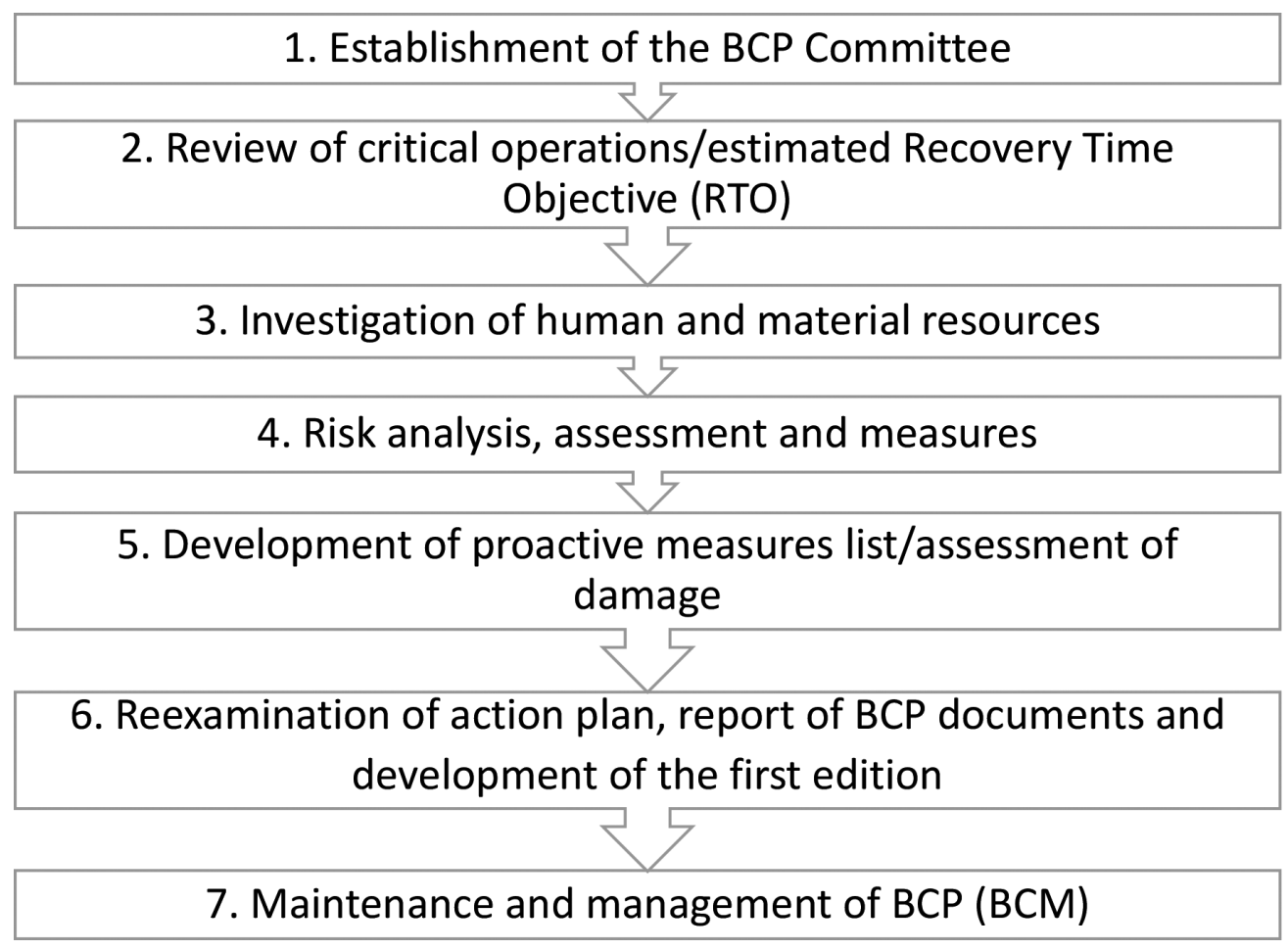

Fig. 3. Process to develop the TUH BCP.

A brief committee meeting was held once a month, where various kinds of investigations were carried out. Each investigation (each step) took one month except for Steps 3 and 4, which took two months each. The results of this investigation were reported at the next committee meeting to arrive at a consensus.

\section{3) Investigation of human and material resources}

Next, we investigated the kinds and quantity of human and material resources needed to implement critical operations in each department (Fig. 3, Step 3). We took a longer time (two months) for this step, in order to ensure a careful investigation. Considering the availability of current and new resources in view of the $\mathrm{BCM}$, we arrived at the "essential minimum" of human and material resources that are indispensable for the implementation of critical operations.

\section{4) Risk analysis, assessment, and measures}

For risk analysis, assessment, and measures, each department was asked to conduct self-assessment on the achievement of human and material resources (i.e., staff, electricity, water, gas, medical gas, and so on) that was listed in the previous step (Fig. 3, Step 4). If any resource was found insufficient, we asked each department to give concrete solutions. As a result, the integrated list of risk assessment and measures in each department was prepared. It revealed the actual situation of preparedness for each resource. We took two months for this step because business continuity is no less than resource management and proactive measures to implement critical operations.

5) Development of proactive measures list/assessment of damage

On the basis of the above process, we developed a list of proactive measures that we could work on preferentially (Fig. 3, Step 5). These proactive measures were classified into (1) those involving several departments and (2) those that can be solved in each department. The crisis event we assumed in this BCP was defined as an inland earthquake (of seismic intensity $6+$ on the Japan Meteorological Agency scale, the highest being 7) in Sendai where the TUH is located. To assume damage by the earthquake, we referred to the "Sendai City earthquake hazard map" published by the Sendai City Office (Sendai City Office 2002, 2007).

6) Re-examination of the Action Plan, report of $B C P$ documents and development of the first edition

Each department polished their action plan originally generated in 2014 as the specific action protocol (SAP) in this BCP reflecting the experiences during the 2011 GEJET (Fig. 3, Step 6). SAP defines the concrete actions to be taken for the restoration or implementation of critical operations before the RTO at levels from immediately after the onset, up to $3 \mathrm{~m}$ (Fig. 4). We added the concept and general rules for the $\mathrm{BCP}$, resource information of institutional lifelines, and arranged the document architecture. Final approval was obtained from the administration council comprising hospital executives and representatives of all departments. The first edition of TUH BCP was established on November 1, 2017 (Tohoku University Hospital 2019). 
Critical operation time table matrix of Tohoku University Hospital.

\begin{tabular}{|c|l|l|}
\hline Level & Patient safety & Social value \\
\hline C & Critical or death & No contribution / Loss of social trust \\
\hline B & Worsening & Less contribution / Partial trust \\
\hline A & Stable & Full contribution / Full trust \\
\hline
\end{tabular}

\begin{tabular}{|c|c|c|c|c|c|c|c|c|c|c|c|c|c|}
\hline \multirow{2}{*}{$\begin{array}{c}\text { Critical } \\
\text { operation }\end{array}$} & \multirow[t]{2}{*}{ Sub-operation } & \multirow{2}{*}{$\begin{array}{l}\text { Routine } \\
\text { or new }\end{array}$} & \multicolumn{10}{|c|}{ Recovery time objective (RTO) } & \multirow{2}{*}{$\begin{array}{l}\text { Reason for } \\
\text { criticality }\end{array}$} \\
\hline & & & $\begin{array}{c}<1 \\
\mathrm{~h}\end{array}$ & $\begin{array}{l}3 \\
h\end{array}$ & $\begin{array}{l}6 \\
h\end{array}$ & $\begin{array}{c}12 \\
h\end{array}$ & $\begin{array}{c}24 \\
h\end{array}$ & $\begin{array}{l}3 \\
d\end{array}$ & $\begin{array}{c}1 \\
w\end{array}$ & $\begin{array}{c}2 \\
w\end{array}$ & $\begin{array}{l}1 \\
m\end{array}$ & $\begin{array}{l}3 \\
m\end{array}$ & \\
\hline \multirow{3}{*}{$\begin{array}{l}\text { Security } \\
\text { assurance }\end{array}$} & Staff & \multirow[t]{3}{*}{ Routine } & & & & & & & & & & & \multirow[t]{3}{*}{ Unstoppable } \\
\hline & Infrastructure & & & & & & & & & & & & \\
\hline & Patients and visitors & & & & & & & & & & & & \\
\hline \multirow[t]{2}{*}{ Life support } & Staff & \multirow[t]{2}{*}{ New } & & & & & & & & & & & \multirow{2}{*}{$\begin{array}{l}\text { Including support } \\
\text { for families }\end{array}$} \\
\hline & Patient & & & & & & & & & & & & \\
\hline \multirow{4}{*}{$\begin{array}{l}\text { Mass } \\
\text { casualty } \\
\text { treatment }\end{array}$} & Triage area & \multirow[t]{4}{*}{ New } & & & & & & & & & & & \multirow{4}{*}{$\begin{array}{l}\text { Social need as } \\
\text { the disaster base } \\
\text { hospital (DBH) to } \\
\text { start acceptance } \\
\text { within an hour }\end{array}$} \\
\hline & Outpatient & & & & & & & & & & & & \\
\hline & In-patient & & & & & & & & & & & & \\
\hline & Central facilities & & & & & & & & & & & & \\
\hline \multirow{3}{*}{$\begin{array}{l}\text { Normal } \\
\text { operation }\end{array}$} & Outpatient & \multirow[t]{3}{*}{ Routine } & & & & & & & & & & & \multirow{3}{*}{$\begin{array}{l}\text { Return to the } \\
\text { normal operation } \\
\text { within } 2 \text { weeks. }\end{array}$} \\
\hline & In-patient & & & & & & & & & & & & \\
\hline & Central facilities & & & & & & & & & & & & \\
\hline \multicolumn{2}{|c|}{ Support for regional health facilities } & New & & & & & & & & & & & Role as DBH \\
\hline
\end{tabular}

Fig. 4. The list of critical operations and estimated RTO.

This is a representative table of entire hospital. Every department should have a similar individual table.

Each row contains department name, critical operations and estimated RTO (colored column). Green means there is no impact on patient's health condition or social trust to the hospital; yellow means there is a possibility that some patient's condition may be aggravated or partial loss of social trust; Red means there is a possibility that some patient may die, and the loss of social trust.

Before the column turns into red from yellow, each department must resume the critical operations by alternative methods or resources. By introducing the idea of RTO, we can prioritize the critical operations.

\section{7) Maintenance and management of $B C P(B C M)$}

$\mathrm{BCP}$ should be periodically updated as untreated BCPs become worthless. It is necessary to enhance the effectiveness of BCPs through training. TUH has addressed the following items for BCM: (1) the solution of problems using the list of proactive measures through small group meetings involving relevant departments, (2) BCP development for new departments including the obstetrics and perinatal care units, psychiatry wards, infectious disease wards, and some specific inpatient wards as a step toward implementing department-specific BCPs throughout the hospital, (3) BCP exercise and training including tabletop exercises, emergency facility inspection training with external maintenance suppliers, and educational lectures. We will renew our TUH BCP annually. The third edition is under development (Fig. 3, Step 7).

\section{Discussion}

If a disaster occurs, the public health and medical needs increase rapidly. The surge in needs usually far exceeds the daily level of the capacity to respond to it. The provision and capacity of public health and medical service will decrease for a while because of the impact of the disaster. This is a specific feature of social safety organizations such as public health, medical, police, fire department, and governmental administrations while framing a BCP. The reasons for such business level fluctuations are: (1) there are special operations that should not have any downtime even during routine operations (i.e., patient care with mechanical ventilators), (2) new operations should be able to cope with surge needs after a disaster (i.e., accepting mass casualty, dispatching staff), and (3) additional operations for restoration of damaged facilities and systems. Every public health and medical organization should recover as quickly as possible after a catastrophe by relying on its BCP and BCM to reduce the operational burden at the peak and to shorten the restoration time. Quick recovery of the health sector leads to quick recovery of the affected community, and trust is gained from society. Every public health and medical organization has to establish a $\mathrm{BCP}$ and $\mathrm{BCM}$.

During the 2011 GEJET, we felt a terrible shake that we had never experienced before, but hospital buildings did not collapse and neither the staff nor patients were injured. Nevertheless, we suffered from the long-term stoppage of lifelines and lack of human and material resources. We realized that countermeasures against an earthquake needs not only to build an aseismic building structurally but also 
to take functional measures for the long-term stoppage of lifelines and human and material resource that occur as a result of any kind of disaster. There should be a common concept in place as hospital and health care staff prepare to respond to health crises regardless of the type of hazards they face. Hospital BCPs and BCM form the structured tool that can strengthen hospital resilience during a disaster.

The component that should be included in a hospital $\mathrm{BCP}$ may change according to the frequency and type of hazard, geographical and historical background, and hospital systems. Combining the results of the scoping review and our own experience of the 2011 GEJET, we suggest that the following points are integral, universal components that must be considered for inclusion in hospital BCPs:

i. Alternative methods and resources

ii. Priority of operations

iii. Resource management.

While considering alternatives, hospital evacuation is among the most difficult choices to make, as many authors have mentioned (Bagaria et al. 2009; Adini et al. 2012; Petinaux and Yadav 2013). Many problems pertaining to hospital evacuation, such as evacuation criteria, how to transport a patient on life support, and where to transport inpatients, remain unsolved and are repeatedly faced during disasters. Even though hospital evacuation can be planned before a disaster, it is very difficult if it is necessary suddenly. Hospital BCPs should contain the assumption of hospital evacuation needs.

It is impossible to carry out quick and effective disaster response and restoration processes without a process of "selection and concentration" in handling limited human and material resources. During the 2018 torrential rains in west Japan, a hospital in which the director had decided on the priority of business restorations and RTO got an earlier restart when compared to a hospital that had a plan without an RTO (Yuasa et al. 2019). It is important to decide on critical operations and hospital policies based on how the hospital should contribute to the community during a disaster. This decision needs the understanding and determination of hospital executives.

The capacity and planning necessary to receive support should be considered an important component of resource management. A hospital can survive and restore the affected area by receiving and utilizing support from outside efficiently. At the time of the 2011 GEJET, we found that the support received largely depended on how or to whom the support would be ordered, and who would manage it (Sasaki et al. 2015). As the opportunity to receive support (becoming a hospital affected by disaster) is very rare, capacity building through education is critical. Potential recipients cannot build up their capability of receiving support without appropriate imagination, education, and training.

In Japan, the Ministry of Health, Labour and Welfare (MHLW) made it mandatory for every DBH to establish its own $\mathrm{BCP}$ and to conduct training (Ministry of Health
2018). However, non-DBH, which accounts for $90 \%$ of Japanese hospitals, are not mandated to do so. A hospital must play the role of a community safety structure in collaboration with other medical and relevant organizations during a disaster. As a disaster can strike anywhere, at any time, and target anybody, DBH, non-DBH, and other relevant organizations should develop their own BCPs and BCM. Developing a BCP and BCM itself takes a lot of time and effort but leads to fruitful results and future.

\section{Limitations}

In this scoping review, we searched the literature listed on PubMed extensively. However, we did not look up other databases. Thus, there may be some relevant articles that were not selected. It was not possible to directly compare the diversity in the type of hazards, loco-regional contexts of vulnerability, and coping capacity including the difference in health insurance, public health and medical systems, and cultural differences, in the literature. However, the existence of such a difference itself suggests the necessity for BCPs and BCM in each context in any hospital in the world.

\section{Conclusion}

Through this scoping review, we found a universal and common feature of hospital BCPs with a diverse range of variabilities based on the era, region, types of hazards, regional and local contexts of vulnerability, and coping capacities. Considering such characteristics and our unforeseen experiences of the 2011 GEJET, we suggest the following point as universal components for hospital BCPs with fewer assumptions of specific hazards so that our hospital can be resilient in dealing with various situations during a disaster: alternative methods and resources, priority of operations, and resource management. Regardless of the type of hazard and loco-regional context, the development of BCPs and BCM adopting integral components while considering various types of disaster damage can help build hospital resilience to address disasters in the future.

\section{Acknowledgments}

The authors would like to thank administrative members, Makoto Abe, Chikara Sakurai, Ikunori Yamazaki, Toru Okada, and Kentaro Ujiie from the Division of Structure Design and Yasuo Yoshida and Ichiro Sasaki from the Division of Administration at the Tohoku University Hospital for their tireless cooperation in the development of TUH BCP. This work was supported by JSPS KAKENHI Grant Number JP19K10478. We would like to thank Editage (https://www.editage.com) for English language editing.

\section{Conflict of Interest}

The authors declare no conflict of interest. 


\section{References}

Abramovich, M.N., Hershey, J.C., Callies, B., Adalja, A.A., Tosh, P.K. \& Toner, E.S. (2017) Hospital influenza pandemic stockpiling needs: a computer simulation. Am. J. Infect. Control, 45, 272-277.

Adini, B., Laor, D., Cohen, R. \& Israeli, A. (2012) Decision to evacuate a hospital during an emergency: the safe way or the leader's way? J. Public Health Policy, 33, 257-268.

Apisarnthanarak, A., Mundy, L.M., Khawcharoenporn, T. \& Glen Mayhall, C. (2013) Hospital infection prevention and control issues relevant to extensive floods. Infect. Control Hosp. Epidemiol., 34, 200-206.

Ardalan, A., Kandi Keleh, M., Saberinia, A., Khorasani-Zavareh, D., Khankeh, H., Miadfar, J., Maleknia, S., Mobini, A. \& Mehranamin, S. (2016) 2015 estimation of hospitals safety from disasters in I.R.Iran: the results from the assessment of 421 hospitals. PLoS One, 11, e0161542.

Arksey, H. \& O'Malley, L. (2005) Scoping studies: towards a methodological framework. Int. J. Soc. Res. Methodol., 8, 19-32.

Asefzadeh, S., Varyani, A.S. \& Gholami, S. (2016) Disaster risk assessment in educational hospitals of Qazvin based on WHO pattern in 2015. Electron. Physician, 8, 1770-1775.

Bagaria, J., Heggie, C., Abrahams, J. \& Murray, V. (2009) Evacuation and sheltering of hospitals in emergencies: a review of international experience. Prehosp. Disaster Med., 24, 461-467.

Buehler, J.W., Whitney, E.A. \& Berkelman, R.L. (2006) Business and public health collaboration for emergency preparedness in Georgia: a case study. BMC Public Health, 6, 285.

Cabinet Office, Government of Japan (2013) Fact-finding investigation about the business continuity in the supecific fields. http://www.bousai.go.jp/kyoiku/kigyou/topics/pdf/jigyou_ keizoku_02.pdf

[Accessed: August 16, 2019] (in Japanese).

Carlton, P.K. \& Bringle, D. (2012) Business continuity after catastrophic medical events: the Joplin medical business continuity report. Am. J. Disaster Med., 7, 321-331.

Christian, M.D., Devereaux, A.V., Dichter, J.R., Rubinson, L. \& Kissoon, N. (2014) Introduction and executive summary: care of the critically ill and injured during pandemics and disasters: CHEST consensus statement. Chest, 146, 8s-34s.

Daugherty, E.L. (2008) Health care worker protection in mass casualty respiratory failure: infection control, decontamination, and personal protective equipment. Respir. Care, 53, 201-212; discussion 212-214.

Djalali, A., Ardalan, A., Ohlen, G., Ingrassia, P.L., Corte, F.D., Castren, M. \& Kurland, L. (2014) Nonstructural safety of hospitals for disasters: a comparison between two capital cities. Disaster Med. Public Health Prep., 8, 179-184.

Eastman, A.L., Rinnert, K.J., Nemeth, I.R., Fowler, R.L. \& Minei, J.P. (2007) Alternate site surge capacity in times of public health disaster maintains trauma center and emergency department integrity: Hurricane Katrina. J. Trauma, 63, 253-257.

Egawa, S., Murakami, A. \& Sasaki, H. (2018) Healthy community resilient against disaster. In The 2011 Japan Earthquake and Tsunami: Reconstruction and Restoration. Springer, pp. 139-152.

Furukawa, H., Kudo, D., Nakagawa, A., Matsumura, T., Abe, Y., Konishi, R., Yamanouchi, S., Ishibashi, S., Kobayashi, M., Narita, N., Washio, T., Arafune, T., Tominaga, T. \& Kushimoto, S. (2014) Hypothermia in victims of the great East Japan earthquake: a survey in Miyagi prefecture. Disaster Med. Public Health Prep., 8, 379-389.

Gamble, K.H. (2008) Weathering the storm. Having a disaster recovery plan can mean the difference between scrambling for a quick IT fix and smooth sailing in the storm. Healthc. Inform., 25, 32, 34, 36-38.
Gomes, R. \& Lapao, L.V. (2008) The adoption of IT security standards in a healthcare environment. Stud. Health Technol. Inform., 136, 765-770.

Graham, K. \& Connolly, M. (2007) Health systems planning for an influenza pandemic. Healthc. Manage. Forum, 20, 25-31.

Heidaranlu, E., Ebadi, A., Ardalan, A. \& Khankeh, H. (2015) A scrutiny of tools used for assessment of hospital disaster preparedness in Iran. Am. J. Disaster Med., 10, 325-338.

Hirata, N. \& Kimura, R. (2018) The earthquake in Osaka-fu hokubu on 18 June 2018 and its ensuing disaster. J. Disaster Res., 13, 813-816.

Hoffman, A., Fagan, H., Casas-Melley, A., Wei, J. \& Hebra, A. (2018) Hurricane irma impact on the inpatient population at a tertiary children's hospital in Florida. Am. Surg., 84, 13951400.

Horvath, J.S., McKinnon, M. \& Roberts, L. (2006) The Australian response: pandemic influenza preparedness. Med. J. Aust., 185, S35-38.

Icenogle, M., Eastburn, S. \& Arrieta, M. (2016) Katrina's legacy: processes for patient disaster preparation have improved but important gaps remain. Am. J. Med. Sci., 352, 455-465.

Inter-ministerial Avian Influenza Committee (2007) Pandemic influenza preparedness action plan of the Japanese government.

https://www.mhlw.go.jp/english/topics/influenza/dl/ pandemic02.pdf [Accessed: August 16, 2019].

Ishigaki, A., Higashi, H., Sakamoto, T. \& Shibahara, S. (2013) The Great East-Japan Earthquake and devastating tsunami: an update and lessons from the past Great Earthquakes in Japan since 1923. Tohoku J. Exp. Med., 229, 287-299.

Itzwerth, R.L., Macintyre, C.R., Shah, S. \& Plant, A.J. (2006) Pandemic influenza and critical infrastructure dependencies: possible impact on hospitals. Med. J. Aust., 185, S70-72.

Kandel, N. (2015) Is there a business continuity plan for emergencies like an Ebola outbreak or other pandemics? J. Bus. Contin. Emer. Plan., 8, 295-298.

Kearns, R.D., Conlon, K.M., Valenta, A.L., Lord, G.C., Cairns, C.B., Holmes, J.H., Johnson, D.D., Matherly, A.F., Sawyer, D., Skarote, M.B., Siler, S.M., Helminiak, R.C. \& Cairns, B.A. (2014) Disaster planning: the basics of creating a burn mass casualty disaster plan for a burn center. J. Burn. Care Res., 35, e1-e13.

Khorasani, R. (2008) Business continuity and disaster recovery: PACS as a case example. J. Am. Coll. Radiol., 5, 144-145.

King, M.A., Niven, A.S., Beninati, W., Fang, R., Einav, S., Rubinson, L., Kissoon, N., Devereaux, A.V., Christian, M.D. \& Grissom, C.K. (2014) Evacuation of the ICU: care of the critically ill and injured during pandemics and disasters: CHEST consensus statement. Chest, 146, e44S-60S.

Koonin, L.M. (2020) Novel coronavirus disease (COVID-19) outbreak: now is the time to refresh pandemic plans. J. Bus. Contin. Emer. Plan., 13, 1-15.

Kudo, D., Furukawa, H., Nakagawa, A., Abe, Y., Washio, T., Arafune, T., Sato, D., Yamanouchi, S., Ochi, S., Tominaga, T. \& Kushimoto, S. (2014) Reliability of telecommunications systems following a major disaster: survey of secondary and tertiary emergency institutions in Miyagi Prefecture during the acute phase of the 2011 Great East Japan Earthquake. Prehosp. Disaster Med., 29, 204-208.

Kudo, D., Furukawa, H., Nakagawa, A., Yamanouchi, S., Koido, Y., Matsumura, T., Abe, Y., Konishi, R., Matoba, M., Tominaga, T. \& Kushimoto, S. (2013) Resources for business continuity in disaster-based hospitals in the great East Japan earthquake: survey of Miyagi Prefecture disaster base hospitals and the prefectural disaster medicine headquarters. Disaster Med. Public Health Prep., 7, 461-466.

Kuroda, T., Kimura, E., Matsumura, Y., Yamashita, Y., Hiramatsu, H. \& Kume, N. (2013a) Simulating cloud environment for 
HIS backup using secret sharing. Stud. Health Technol. Inform., 192, 171-174.

Kuroda, T., Kimura, E., Matsumura, Y., Yamashita, Y., Hiramatsu, H., Kume, N. \& Sato, A. (2013b) Applying secret sharing for HIS backup exchange. Conf. Proc. IEEE Eng. Med. Biol. Soc., 2013, 4179-4182.

Landman, A., Teich, J.M., Pruitt, P., Moore, S.E., Theriault, J., Dorisca, E., Harris, S., Crim, H., Lurie, N. \& Goralnick, E. (2015) The Boston Marathon bombings mass casualty incident: one emergency department's information systems challenges and opportunities. Ann. Emerg. Med., 66, 51-59.

Langer, S.G., Wood, C.P., Murthy, N.S., French, T.L. \& Rubin, M. (2012) PACS bypass: a semi-automated routing solution to enable filmless operations when PACS fails. J. Digit. Imaging, 25, 466-470.

Lowe, C.G. (2009) Pediatric and neonatal interfacility transport medicine after mass casualty incidents. J. Trauma, 67, S168171.

Luecke, R.W. \& Hoopingarner, C. (1993) Business continuity planning: the hospital's insurance policy. Healthc. Financ. Manage., 47, 30, 32-37.

Matsumura, T., Osaki, S., Kudo, D., Furukawa, H., Nakagawa, A., Abe, Y., Yamanouchi, S., Egawa, S., Tominaga, T. \& Kushimoto, S. (2015) Water supply facility damage and water resource operation at disaster base hospitals in miyagi prefecture in the wake of the Great East Japan Earthquake. Prehosp. Disaster Med., 30, 193-198.

Ministry of Economy, Trade and Industry (2005) The guideline for business continuity plan establishment.

https://www.meti.go.jp/policy/netsecurity/downloadfiles/6_ bcpguide.pdf [Accessed: June 26, 2020] (in Japanese)

Ministry of Health, Labour and Welfare (2018) About partial revision of disaster base hospital designate requirement. https://www.mhlw.go.jp/content/10800000/000356993.pdf [Accessed: August 16, 2019] (in Japanese).

Moher, D., Liberati, A., Tetzlaff, J. \& Altman, D.G. (2009) Preferred reporting items for systematic reviews and metaanalyses: the PRISMA statement. PLoS Med., 6, e1000097.

Moradian, M.J., Ardalan, A., Nejati, A., Boloorani, A.D., Akbarisari, A. \& Rastegarfar, B. (2017) Risk criteria in hospital site selection: a systematic review. PLoS Curr, 9, doi: 10.1371/ currents.dis.a6f34643f3cd22c168b8c6f2deeae86d.

Morgan, S.J., Rackham, R.A., Penny, S., Lawson, J.R., Walsh, R.J. \& Ismay, S.L. (2015) Business continuity in blood services: two case studies from events with potentially catastrophic effect on the national provision of blood components. Vox Sang., 108, 151-159.

Nakagawa, A., Furukawa, H., Konishi, R., Kudo, D., Matsumura, T., Sato, D., Abe, Y., Washio, T., Arafune, T., Yamanouchi, S., Kushimoto, S. \& Tominaga, T. (2013) The Great East Japan earthquake: lessons learned at Tohoku University Hospital during the first 72 hours. IEEE Pulse, 4, 20-27.

Newman, B. \& Gallion, C. (2019) Hurricane Harvey: firsthand perspectives for disaster preparedness in graduate medical education. Acad. Med., 94, 1267-1269.

Norcross, E.D., Elliott, B.M., Adams, D.B. \& Crawford, F.A. (1993) Impact of a major hurricane on surgical services in a university hospital. Am. Surg., 59, 28-33.

Oda, N., Hirahara, T., Fujioka, Y., Mitani, R. \& Takata, I. (2019) Legionella pneumonia following the Heavy Rain Event of July 2018 in Japan: a case report. Intern. Med., 58, 2831-2834.

Park, W.S., Seo, S.W., Son, S.S., Lee, M.J., Kim, S.H., Choi, E.M., Bang, J.E., Kim, Y.E. \& Kim, O.N. (2010) Analysis of information security management systems at 5 domestic hospitals with more than 500 beds. Healthc. Inform. Res., 16, 89-99.

Paturas, J.L., Smith, D., Smith, S. \& Albanese, J. (2010) Collective response to public health emergencies and large-scale disasters: putting hospitals at the core of community resil- ience. J. Bus. Contin. Emer .Plan., 4, 286-295.

Perce, K.H. (2007) Disaster recovery: lessons learned from an occupational health and human resources perspective. AAOHN J., 55, 235-240.

Petinaux, B. \& Yadav, K. (2013) Patient-driven resource planning of a health care facility evacuation. Prehosp. Disaster Med., 28, 120-126.

Roberts, P. \& Molyneux, H. (2010) Implementing business continuity effectively within the UK National Health Service. $J$. Bus. Contin. Emer. Plan., 4, 352-359.

Sasaki, H., Yamanouchi, S. \& Egawa, S. (2015) Questionnaire survey on the support-receiving plan of medical institutions affected by the Great East Japan Earthquake and Tsunami (in Japanese). Japanese Journal of Disaster Medicine, 20, 40-50.

Sato, S. \& Imamura, F. (2019) An analysis of web coverage on the 2018 West Japan Heavy Rain Disaster. Journal of Disaster Research, 14, 531-538.

Satomi, S. (2011) The Great East Japan Earthquake: Tohoku University Hospital's efforts and lessons learned. Surg. Today, 41, 1171-1181.

Seltenrich, N. (2018) Safe from the storm: creating climate-resilient health care facilities. Environ. Health Perspect., 126, 102001.

Sendai City Office (2002) Sendai City earthquake damage assumption (summary) in 2002.

http://www.city.sendai.jp/kekaku/kurashi/anzen/saigaitaisaku/ kanren/documents/jisin.pdf

[Accessed: September 9, 2019] (in Japanese).

Sendai City Office (2007) Sendai City Earthquake Hazard Map. http://www.city.sendai.jp/kenchikubosai/kurashi/anzen/ saigaitaisaku/jishintsunami/taisaku/map/index.html [Accessed: June 26, 2020] (in Japanese).

Seyedin, H., Ryan, J. \& Sedghi, S. (2011) Lessons learnt from the past and preparedness for the future: how a developing country copes with major incidents. Emerg. Med. J., 28, 887-891.

Shibahara, S. (2011) The 2011 Tohoku earthquake and devastating tsunami. Tohoku J. Exp. Med., 223, 305-307.

Sprung, C.L. \& Kesecioglu, J. ; European Society of Intensive Care Medicine's Task Force for intensive care unit triage during an influenza epidemic or mass disaster (2010a) Chapter 5. Essential equipment, pharmaceuticals and supplies. Recommendations and standard operating procedures for intensive care unit and hospital preparations for an influenza epidemic or mass disaster. Intensive Care Med., 36 Suppl 1, S38-44.

Sprung, C.L., Zimmerman, J.L., Christian, M.D., Joynt, G.M., Hick, J.L., Taylor, B., Richards, G.A., Sandrock, C., Cohen, R. \& Adini, B. ; European Society of Intensive Care Medicine Task Force for Intensive Care Unit Triage during an Influenza Epidemic or Mass Disaster (2010b) Recommendations for intensive care unit and hospital preparations for an influenza epidemic or mass disaster: summary report of the European Society of Intensive Care Medicine's Task Force for intensive care unit triage during an influenza epidemic or mass disaster. Intensive Care Med., 36, 428-443.

Suginaka, H., Okamoto, K., Hirano, Y., Fukumot, Y., Morikawa, M., Oode, Y., Sumi, Y., Inoue, Y., Matsuda, S. \& Tanaka, H. (2014) Hospital disaster response using business impact analysis. Prehosp. Disaster Med., 29, 561-568.

Sugishita, Y., Soejima, K., Kayebeta, A. \& Yauchi, M. (2019) Enhancing preparedness against rubella at the workplace: proactive prevention efforts by the Tokyo Metropolitan Government. Jpn. J. Infect. Dis., 72, 250-255.

Takeuchi, K., Matsumura, Y., Akane, H. \& Miki, A. (2019) Research on utilization of LCD monitors substitute for light box about hard-copy diagnosis in an emergency by using receiver operating characteristic analysis. Nihon Hoshasen Gijutsu Gakkai Zasshi, 75, 438-445. 
Tohoku University Hospital (2019) Disaster Prevention and Business Continuity Plan of Tohoku University Hospital -the second edition-.

https://www.hosp.tohoku.ac.jp/pc/pdf/bcp1.pdf

[Accessed: August 18, 2019] (in Japanese).

Tomizuka, T., Kanatani, Y. \& Kawahara, K. (2013) Insufficient preparedness of primary care practices for pandemic influenza and the effect of a preparedness plan in Japan: a prefecturewide cross-sectional study. BMC Fam. Pract., 14, 174.

Tosh, P.K., Feldman, H., Christian, M.D., Devereaux, A.V., Kissoon, N. \& Dichter, J.R. ; Task Force for Mass Critical Care (2014) Business and continuity of operations care of the critically ill and injured during pandemics and disasters: CHEST consensus statement. Chest, 146, e103s-e117s.

World Health Organization (WHO)(2015) Hospital safety index: guide for evaluators, 2 nd ed.

https://www.who.int/hac/techguidance/hospital_safety_index_ evaluators.pdf

[Accessed: September 6, 2019].

Yamanouchi, S., Sasaki, H., Kondo, H., Mase, T., Otomo, Y., Koido, Y. \& Kushimoto, S. (2017) Survey of preventable disaster deaths at medical institutions in areas affected by the Great East Japan Earthquake: retrospective survey of medical institutions in Miyagi Prefecture. Prehosp. Disaster Med., 32, 515-522.

Yamanouchi, S., Sasaki, H., Tsuruwa, M., Ueki, Y., Kohayagawa, Y., Kondo, H., Otomo, Y., Koido, Y. \& Kushimoto, S. (2015) Survey of preventable disaster death at medical institutions in areas affected by the Great East Japan Earthquake: a retrospective preliminary investigation of medical institutions in Miyagi Prefecture. Prehosp. Disaster Med., 30, 145-151.

Yuasa, Y., Nakano, S. \& Okano, M. (2019) Initial response and business continuity in case of inundation damage of medical institutions. Journal of JSCE, 75, I_217-I_226.

Zimmerman, J.L. \& Sprung, C.L. ; European Society of Intensive Care Medicine's Task Force for intensive care unit triage during an influenza epidemic or mass disaster (2010) Chapter 8. Medical procedures. Recommendations and standard operating procedures for intensive care unit and hospital preparations for an influenza epidemic or mass disaster. Intensive Care Med., 36 Suppl 1, S65-69. 